\title{
EDITORIAL
}

\section{Improving neonatal mortality in sub-Saharan Africa: any cause for optimism?}

\author{
Journal of Perinatology (2011) 31, 745-748; doi:10.1038/jp.2011.53
}

Of the estimated 8.8 million annual deaths that occur in children under the age of 5 years, $41 \%$ occur in neonates. ${ }^{1}$ Thus, per day, the newborn is 45 times more likely to die within the first 28 days of life than in the entire period from 4 weeks to 5 years of age. More than $98 \%$ of neonatal deaths occur in low- and middleincome countries and approximately $70 \%$ occur in community settings, often the home. ${ }^{2}$ These deaths frequently take place outside the formal health system and are rarely included in the vital registration process. ${ }^{3,4}$

Sub-Saharan countries have among the highest neonatal mortality rates in the world, yet some of the weakest health and vital registration systems. ${ }^{5,6}$ As an example, complete data on cause of neonatal death are lacking for over $97 \%$ of neonatal deaths in this region and neonatal mortality rates are often underestimated. ${ }^{7-9}$ The dearth of accurate, populationbased, neonatal data that recognize and count the most common antecedents and causes of neonatal death poses significant challenges to developing a coherent neonatal health policy. ${ }^{10}$

Conducting community-based interdisciplinary research on newborn health in low- and middle-income countries is complex, time consuming and poses formidable challenges often underappreciated by clinicians or clinical trialists working in hospital settings. In addition to cultural, linguistic and disciplinary differences, logistic challenges include negotiating country-specific Ministry of Health bureaucracies, the need to submit multiple institutional review board (IRB) applications to multiple IRBs with differing requirements and application forms, often in different languages, and creating standardized Manuals of Operation that conform (in multi-country studies) to each country's clinical and public health position statements. In many rural settings there are strong cultural beliefs that preclude discussing the deceased newborn, and a belief that the dead child was a 'spirit child'. Often the child is not named before death, and is therefore not 'socially or culturally born'. Burials are therefore quick and without ceremony, lacking formal expressions of grief for fear that the family may become recipients of supernatural malevolent harm. ${ }^{11-13}$

In this Journal of Perinatology, Diallo et al. ${ }^{14}$ report their findings from an important study designed to enumerate neonatal mortality and investigate its predictors in rural Burkina Faso in West Africa. The authors enrolled 864 infants whom they followed from birth until 6 months of age in 24 villages in the Bonfora Health District. The authors utilized a technique known as verbal autopsy, which has been developed to address the lack of cause of death (COD) data from deaths that occur in community settings. Verbal autopsy is an indirect method of ascertaining COD where civil registration and health systems are weak. ${ }^{15}$ During verbal autopsy, a systematic description of the signs, symptoms and circumstances preceding death is obtained through an interview with the primary care-giver (usually the mother of the deceased infant) ${ }^{16} \mathrm{~A}$ variety of methods exist for interpreting verbal autopsy interviews to arrive at a COD. The most commonly used method has two or three trained physician coders who review the data and independently assign a COD. Any discrepancy between the COD assigned by each physician member of the panel is resolved by discussion and review of the verbal autopsy data, and a final consensus COD is agreed upon by the physician panel. Alternatively, COD can be assigned by the use of predetermined criteria/algorithms, computer simulations or probabilistic methods such as Inter verbal autopsy. ${ }^{17,18}$ This technique has been extensively validated and is applied in over 49 countries, including India and China, at scale. ${ }^{19}$ Verbal autopsy is also used to investigate outbreaks of infectious diseases, measure risk factors for certain diseases, and assess the effect of public health interventions. In the Burkino Faso study, physicians used a hierarchy adapted from the Child Health Epidemiology Reference Group Classification and the International Classification of Diseases 10th edition. ${ }^{20}$ This arranges COD in a particular order based primarily on the specificity and sensitivity of the causal definition, and the presumed physiological precedence of each cause's contribution to a death. As each COD is identified, cases assigned to the cause are sequentially removed from the sample and cannot be assigned another COD. ${ }^{21}$

The authors report a neonatal mortality rate of 46.3 deaths per 1000 live births. In multivariate regression, they identified twin birth, a nulliparous mother and birth into a polygamous household as the main predictors of neonatal death. Other authors have identified prematurity and low birth weight as additional factors associated with higher risks of neonatal death in sub-Saharan Africa. ${ }^{2,6,22}$

A closer examination of the mothers and antenatal history of the women in this study suggests similarities with many other 
settings in sub-Saharan Africa (relatively few nulliparous women, low literacy, and two or fewer antenatal care visits), although the authors point out that this population is from a relatively wealthy district in Burkina Faso. Of the neonates who died, the majority died within the first 7 days, mostly in the home, and without interfacing with the formal health system. This finding is in keeping with much of the published literature to date. ${ }^{7,21}$ The authors also engage in a lively discussion on the relative socio-biological antecedents associated with the neonatal deaths, of which poor quality of health care, geographically inaccessible health facilities and de-motivated health personnel dominate. They conclude by suggesting that given the high neonatal mortality rates among rural populations in Burkina Faso, Millennium Development Goal 4, which proposes a reduction of under-five deaths by two-thirds by 2015 (MDG declaration 2000), is unlikely to be achieved.

Since the Alma Ata declaration which highlighted the importance of community-based primary health care, is a major pivot for attaining MDG 4, and as there is now an increased awareness that most newborn deaths occur in the home, are there success stories and lessons learned that may provide some optimism for reducing neonatal deaths through a communitybased approach? Nair et al. ${ }^{23}$ provide a useful conceptual model mediated through three broad strategies.

\section{Community engagement and mobilization}

The Warmi program worked with rural Aymara women's groups with limited access to modern medical facilities in remote Bolivia. The intervention focused on initiating and strengthening women's organizations, developing women's skills in problem identification, prioritizing and evolving local strategies to improve maternal and newborn health, and evaluating outcomes. Perinatal mortality decreased from 117 deaths per 1000 births before the intervention to 43.8 deaths per 1000 birth after. ${ }^{24}$ Manandhar et al., ${ }^{25}$ in a modified version of this process in rural Nepal, conducted a cluster randomized trial that suggested that women's groups, facilitated by a local female community health worker trained in facilitation techniques but without a health-care background, could reduce neonatal mortality rates by $30 \%$. They report that approximately three-quarters of the groups remained active for 18 months after withdrawal of program support. A similar process is occurring through the MaiMwama program in Malawi, where in addition to trained female facilitators identified by local communities, volunteer counselors are trained in nutrition, breastfeeding, prevention of mother-to-child transmission and birth preparedness counseling. ${ }^{26}$ Within West Africa, the Senegalese Health Hut system appears to be successfully utilizing community-based strategies to improve newborn health in poor, rural communities. Working hand-in-hand with Senegal's health districts, a consortium of stakeholders ensure that families have easy access to more than
1350 local health huts, run by trained volunteers who live in the community. The health huts, with a special focus on maternal and child health, oversee prevention and treatment of basic illnesses, refer serious cases to the nearest government health facility, and promote health education for the entire community. ${ }^{27}$ The community, mobilized by influential traditional, religious and group leaders, is integral in recognizing the health gaps, choosing its vectors (traditional birth attendants (TBAs), community health workers and village agents) and paying them. Regular training and supervision of these volunteers by skilled health workers such as nurses, midwives and doctors is a key ingredient to this model. Groups such as grandmothers, husbands and pregnant mothers have an integral role, thereby ensuring community ownership or 's'approprier', of this program. Although extensive and rigorous assessment of the data from the health huts system is yet to be undertaken, preliminary program evaluation suggests strong merits. Compared with baseline, there was an increase by $20 \%$ of the following: three or more antenatal care visits by mothers; utilization of iron tablets; and delivery in a health facility and assistance by a skilled birth attendant. Similar increases were noted in mothers' abilities to recognize postpartum danger signs and two or more danger signs in the newborn. ${ }^{28}$

\section{Home-based maternal and child-health management}

One of the main success stories for community-based reduction in newborn mortality has come from Maharashtra, India, through the efforts of the Society for Education, Action and Research (SEARCH). This group trained community health workers to conduct group health education, identify pregnant women and make antenatal care visits to their homes. The community health workers attend the delivery, give vitamin-K injections and make several postnatal visits. These visits focus on identifying and managing infants at risk from sepsis, low birth weight and birth asphyxia, as well as encouraging referral. ${ }^{29,30}$ This model has resulted in a decrease in neonatal mortality by $70 \%$. Similar studies with decreases in neonatal mortality rates of $30-70 \%$ have been reported from Bangladesh, Nepal and Pakistan. Currently there is a WHO study underway in the Democratic Republic of Congo, Nigeria and Kenya, which is investigating the benefits of simplified oral and intramuscular antibiotic regimens for community-based management of possible serious bacterial infection in neonates and young infants. Results from this trial may have promise for reducing further neonatal mortality rates in sub-Saharan Africa.

\section{Partnerships with community health workers and TBAs}

Of the estimated 60 million women who give birth outside of health facilities, 52 million births occur without a skilled birth 
attendant and $15-25$ million are delivered by TBAs annually. ${ }^{31}$ Although TBAs were the subject of considerable debate in the 1980s and 1990s, a recent controlled trial in Pakistan found a 30\% reduction in neonatal mortality when TBA services were linked systematically with government community health workers and obstetric services, while Singhal et al. and Carlo et al. suggest that perinatal mortality rates can be decreased by up to $30 \%$ when TBAs are taught an essential newborn care package. ${ }^{32-34}$ There is also strong evidence that community health workers help mobilize communities to seek care and provide essential newborn services, which may reduce perinatal mortality by $30 \%{ }^{35}$

Over the past decade, there has been increasing recognition within the global health community of the extraordinarily high mortality burden that occurs within the neonatal period. This has resulted in an explosion of funding for research and programmatic efforts to determine best practices and policies associated with improving newborn health. Focused programs such as the AAP/AHA Neonatal Resuscitation program and the WHO Essential Newborn Care program have been updated significantly. These, in addition to the recently launched USAID/SNL/WHO Helping Babies Breathe program and controlled trials such as those through the African Newborn Network, are currently underway to assess their applicability in a variety of African settings. Also, several qualitative studies that span the continuum of care across the antenatal, labor and delivery, immediate newborn, and postpartum periods ${ }^{36}$ and that are designed to understand the local context in which maternal and neonatal health is managed are underway. As these periods, culturally, are imbued with tremendous cultural import and may involve strong adherence to local practices, an enhanced understanding of the knowledge, perceptions and practices of household and formal health-care providers has important ramifications for overall neonatal mortality. For example, our work in the Navrongo Health and Demographic Surveillance System (NHDSS) has shown that of 19000 deliveries, $65 \%$ occurred in a health facility delivery, with skilled attendant advice regarding optimal cord care. Yet, well over $87 \%$ of mothers, once they went home, used some local, non-prescribed paste such as shea butter.

Finally, as successful programs have shown, active engagement of the community in recognizing and developing effective methods that address newborn mortality and that continually inputs program data that aid in reassessment and refinements is essential. This concerted mortality push to highlight the scale of the neonatal problem and to begin investigating potential novel solutions is an encouraging start to an enhanced neonatal health policy in many countries in sub-Saharan Africa.

\section{Conflict of interest}

The author declares no conflict of interest.

\author{
C Engmann \\ ${ }^{1}$ Departments of Pediatrics and Maternal Child Health, \\ Schools of Medicine and Public Health, University of \\ North Carolina at Chapel Hill, Chapel Hill, NC, USA \\ E-mail:cengmann@med.unc.edu
}

\section{References}

1 Black RE, Cousens S, Johnson HL, Lawn JE, Rudan I, Bassani DG et al. Global, regional, and national causes of child mortality in 2008: a systematic analysis. Lancet 2010; 375(9730): 1969-1987.

2 Lawn JE, Cousens S, Zupan J. 4 million neonatal deaths: When? Where? Why? Lancet 2005; 365(9462): 891-900.

3 Mathers $\mathrm{CD}$, Fat DM, Inoue M, Rao C, Lopez AD. Counting the dead and what they died from: an assessment of the global status of cause of death data. Bull World Health Organ 2005; 83(3): 171-177.

4 Setel PW, Macfarlane SB, Szreter S, Mikkelsen L, Jha P, Stout S et al. A scandal of invisibility: making everyone count by counting everyone. Lancet 2007; 370(9598): 1569-1577.

5 Baiden F, Hodgson A, Adjuik M, Adongo P, Ayaga B, Binka F. Trend and causes of neonatal mortality in the Kassena-Nankana district of northern Ghana, 1995-2002. Trop Med Int Health 2006; 11(4): 532-539.

6 Engmann C, Matendo R, Kinoshita R, Ditekemena J, Moore J, Goldenberg RL et al. Stillbirth and early neonatal mortality in rural Central Africa. Int J Gynaecol Obstet 2009; 105(2): 112-117.

7 Engmann C, Jehan I, Ditekemena J, Garces A, Phiri M, Mazariegos M et al. Using verbal autopsy to ascertain perinatal cause of death: are trained non-physicians adequate? Trop Med Int Health 2009; 14(12): 1496-1504.

8 Stumbling around in the dark. Lancet 2005; 365(9476): 1983.

9 Lawn J, Shibuya K, Stein C. No cry at birth: global estimates of intrapartum stillbirths and intrapartum-related neonatal deaths. Bull World Health Organ 2005; 83(6): 409-417.

10 Lopez $\mathrm{AD}$, Mathers $\mathrm{CD}$. Measuring the global burden of disease and epidemiological transitions: 2002-2030. Ann Trop Med Parasitol 2006; 100(5-6): 481-499.

11 Adetunji JA. Preserving the pot and water: a traditional concept of reproductive health in a Yoruba community, Nigeria. Soc Sci Med 1996; 43(11): 1561-1567.

12 Allotey P, Reidpath D. Establishing the causes of childhood mortality in Ghana: the 'spirit child'. Soc Sci Med 2001; 52(7): 1007-1012.

13 Winch PJ, Alam MA, Akther A, Afroz D, Ali NA, Ellis AA et al. Local understandings of vulnerability and protection during the neonatal period in Sylhet District, Bangladesh: a qualitative study. Lancet 2005; 366(9484): 478-485.

14 Diallo AH, Meda N, Ouédraogo WT, Cousens S, Tylleskar T. A prospective study on neonatal mortality and its predictors in a rural area in Burkina Faso: Can MDG-4 be met by 2015? J Perinatol 2011; (this issue).

15 Soleman N, Chandramohan D, Shibuya K. Verbal autopsy: current practices and challenges. Bull World Health Organ 2006; 84(3): 239-245.

16 Garenne M, Fauveau V. Potential and limits of verbal autopsies. Bull World Health Organ 2006; 84(3): 164.

17 Byass P, Kahn K, Fottrell E, Collinson MA, Tollman SM. Moving from data on deaths to public health policy in Agincourt, South Africa: approaches to analysing and understanding verbal autopsy findings. PLoS Med 2010; 7(8): e1000325.

18 Engmann C, Jehan I, Ditekemena J, Garces A, Phiri M, Mazariegos M et al. An alternative strategy for perinatal verbal autopsy coding: single versus multiple coders. Trop Med Int Health 2011; 16(1): 18-29.

19 Fottrell E, Byass P. Verbal autopsy: methods in transition. Epidemiol Rev 2010; 32(1): 38-55.

20 Boschi-Pinto C, Young M, Black RE. The Child Health Epidemiology Reference Group reviews of the effectiveness of interventions to reduce maternal, neonatal and child mortality. Int J Epidemiol 2010; 39(Suppl 1): i3-i6.

21 Lawn JE, Wilczynska-Ketende K, Cousens SN. Estimating the causes of 4 million neonatal deaths in the year 2000. Int J Epidemiol 2006; 35(3): 706-718. 
22 Edmond KM, Quigley MA, Zandoh C, Danso S, Hurt C, Owusu Agyei S et al. Aetiology of stillbirths and neonatal deaths in rural Ghana: implications for health programming in developing countries. Paediatr Perinatol Epidemiol 2008; 22(5): $430-437$

23 Nair N, Tripathy P, Prost A, Costello A, Osrin D. Improving newborn survival in lowincome countries: community-based approaches and lessons from South Asia. PLoS Med 2010; 7(4): e1000246.

24 0'Rourke K, Howard-Grabman L, Seoane G. Impact of community organization of women on perinatal outcomes in rural Bolivia. Rev Panam Salud Publica 1998; 3(1): 9-14.

25 Manandhar DS, Osrin D, Shrestha BP, Mesko N, Morrison J, Tumbahangphe KM et al. Effect of a participatory intervention with women's groups on birth outcomes in Nepal: cluster-randomised controlled trial. Lancet 2004; 364(9438): 970-979.

26 Rosato M, Mwansambo CW, Kazembe PN, Phiri T, Soko QS, Lewycka S et al. Women's groups' perceptions of maternal health issues in rural Malawi. Lancet 2006; 368(9542): 1180-1188.

27 Smith LA, Bruce J, Gueye L, Helou A, Diallo R, Gueye B et al. From fever to anti-malarial: the treatment-seeking process in rural Senegal. Malar J 2010; 9: 333 .

28 Sall G. Final evaluation of CANAH Project 11. Christian Children's Fund. August 2006, pp 1-102. http://pdf.usaid.gov/pdf_docs/PDACJ409.pdf (accessed 28 February 2011).
29 Bang AT, Bang RA, Stoll BJ, Baitule SB, Reddy HM, Deshmukh MD. Is home-based diagnosis and treatment of neonatal sepsis feasible and effective? Seven years of intervention in the Gadchiroli field trial (1996 to 2003). J Perinatol 2005; 25(Suppl 1): S62-S71.

30 Bang AT, Paul VK, Reddy HM, Baitule SB. Why do neonates die in rural Gadchiroli, India? (Part I): Primary causes of death assigned by neonatologist based on prospectively observed records. J Perinatol 2005; 25(Suppl 1): S29-S34.

31 Vashishtha VM. The State of the World's Children 2009: maternal health is the key to achieve MDGs 4 and 5. Indian Pediatr 2009; 46(3): 233-234.

32 Carlo WA, Goudar SS, Jehan I, Chomba E, Tshefu A, Garces A et al. Newborn-care training and perinatal mortality in developing countries. N Engl J Med 2010; 362(7): $614-623$.

33 Jokhio AH, Winter HR, Cheng KK. An intervention involving traditional birth attendants and perinatal and maternal mortality in Pakistan. $N$ Engl J Med 2005; 352(20): 2091-2099.

34 Singhal N, Bhutta ZA. Newborn resuscitation in resource-limited settings. Semin Fetal Neonatal Med 2008; 13(6): 432-439.

35 Darmstadt GL, Lee AC, Cousens S, Sibley L, Bhutta ZA, Donnay F et al. 60 Million nonfacility births: who can deliver in community settings to reduce intrapartum-related deaths? Int J Gynaecol Obstet 2009; 107(Suppl 1): S89-S112.

36 Marsh DR, Darmstadt GL, Moore J, Daly P, Oot D, Tinker A. Advancing newborn health and survival in developing countries: a conceptual framework. J Perinatol 2002; 22(7): $572-576$ 